\title{
Fibre optic sensor enabled containment zone
}

\author{
Preetam Suman $^{\mathrm{a}}$, Deepak K Singh ${ }^{\mathrm{b}}$, Richa Srivastava ${ }^{\mathrm{c}}$ \\ a,b,c Jaipuria Institute of Management, Lucknow \\ Preetam.suman@jaipuria.ac.in ${ }^{\mathrm{a}}$, d.singh@jaipuria.ac.in ${ }^{\mathrm{b}}$, richa.srivastava@jaipuria.ac.in ${ }^{\mathrm{c}}$
}

Article History: Received: 10 November 2020; Revised 12 January 2021 Accepted: 27 January 2021; Published online: 5 April 2021

\begin{abstract}
There are many sensitive areas like country borders, banks, forests, army cantonments, jails which requires continuous monitoring and surveillance. Intruders and illegal elements try to break the security and enter into these areas. In the same way there is another sensitive zone called containment zone required protection to prevent spread of viruses like corona. Every country has established their own protocols to maintain containment zone. Security officials monitored the sensitive areas but still it was not safe enough. In this case there is need of an invisible security mechanism which can be applicable in maintaining movements in containment zones. It will be very important to detect any movement in the sensitive area. Therefore, this paper provides a solution to protect sensitive zones. The solution consists of optical fibre sensor along with reporting and alarming system. The design and implementation is explained in the paper along with results. The proposed solution can be implemented to secure zone for multiple applications.
\end{abstract}

Keywords: Fibre optic sensor, containment zone, Covid-19 safety device

\section{Introduction}

Entire world has encountered the tumbling impact of pandemics and each part of human existence has been upset. This emergency most likely is one that has no point of reference - there are no past norms that help governments what to do; how to close down economies; when to re-open; and a how-to leave methodology. We can't deny the way that this infection is a cross-animal varieties transmission - it has hopped from its creature host to people. The effect of Coronavirus on the world is notable. The annihilation brought about by Coronavirus is at its pinnacle. The constraint of annihilation isn't unsurprising. The public authority had given warnings for public wellbeing. As indicated by WHO, worldwide has 106,696,325 affirmed instances of Covid, with an aggregate of 2,327,535 passings (till 08 Feb 2021) [1].

In December 2019, a progression of pneumonia instances of obscure reason distinguished in Wuhan, Hubei, China, with clinical introductions extraordinarily taking after viral pneumonia. After profound sequencing investigation of tests demonstrated a novel Covid, which was named 2019 novel Covid (2019-nCoV). Up to this point, in excess of 800 affirmed cases, including medical care laborers, have been recognized in Wuhan. From that point onward, in an extremely brief timeframe, it spread out in the whole world and was seen as a pandemic. [2, 3, $4,5]$

Till 31 Jan 2021, The United States of America has the most elevated number of cases on the planet - over 27.6 million cases, a fourth of the worldwide aggregate. In any case, the nation has seen a decrease in new cases from past pinnacles. As school and college grounds have re-opened, there have been news reports of understudies testing positive. WHO has distributed direction for school-related general wellbeing measures with regards to COVID-19 [1].

As on 31 Jan, South-East Asia has announced the biggest week-on-week increment, to a great extent because of expanded case identifications in India. India has detailed almost 500000 new cases. In Indonesia, cases have been bit by bit expanding while there are likewise worries about transmission among relatives of younger students as $40 \%$ of individuals matured 60 years and more seasoned in Indonesia live in three-age families, implying that they live with their kids and grandkids [1].

Slow expands keep on being seen in the European Region, with Spain, Russia, France, and Ukraine detailing the most noteworthy number of new cases. In the European Region, a large number of the individuals who kicked the bucket of COVID-19 have been old individuals (as of this current week, $88 \%$ of all passings were in people matured 65 years and over). WHO has distributed extensive direction on forestalling and overseeing COVID-19 across long haul care administrations [1]. 
The Eastern Mediterranean Region has noticed a fluctuating frequency of new cases in the long stretches of Feb 2021. The most elevated number of new cases have been found in Iraq, Iran, Morocco, Saudi Arabia, and Kuwait. WHO, in association with the Iraqi Ministry of Health and its executing accomplices, has finished up another round of a COVID-19 mindfulness raising effort that escalated local area outreach endeavors to teach individuals on measures to restrict transmission of COVID-19. [1]

Table 1: COVID-19 cases and deaths, by WHO, data as of 08 Feb 2021 [1]

\begin{tabular}{|l|l|l|}
\hline WHO Region & Total Cases & Total Death \\
\hline Europe & $31,334,540$ & 736,597 \\
\hline North America & $31,604,428$ & 686,208 \\
\hline Asia & $23,584,348$ & 379,650 \\
\hline South America & $16,433,575$ & 428,784 \\
\hline Africa & $3,688,321$ & 95,203 \\
\hline Oceania & 50,392 & 1,078 \\
\hline
\end{tabular}

General wellbeing and social measures have been actualized across the globe by the public authority of various nations. These measures incorporate development limitations, incomplete conclusion or conclusion of schools and organizations, isolate in explicit geographic territories, and global travel limitations. Re-opening of public spots bound to follow defensive measures, including mandates and ability to advance and empower standard COVID19 avoidance as far as physical separating, hand washing, respiratory behavior, and, possibly, warm checking, just as observing consistence with these measures [6].

Choices on shutting or re-opening of working environments and suspension or downscaling of work exercises made considering the danger evaluation, the ability to actualize preventive measures, and proposals of public experts for changing general wellbeing and social measures with regards to COVID-19. Measures for forestalling transmission of COVID-19 incorporates;

Hand cleanliness: Regular and exhaustive handwashing with cleanser and water or hand cleanliness with liquor based hand-rub. Hand cleanliness stations, for example, hand washing and hand rub gadgets, ought to be placed in noticeable spots around the working environment and be made open to all staff [7]

Respiratory cleanliness: Promote respiratory behavior by all individuals at the working environment. Guaranteeing the accessibility of clinical face covers and paper tissues at the work environment [8].

Physical separating: Measures to keep a distance of in any event 1 meter among individuals and stay away from direct actual contact with different people. Diminish the thickness of individuals in the structure (close to one individual for each every 10 square meters) [9], actual dividing at any rate 1 meter separated for work stations and regular spaces, dodging actual gatherings by receiving remotely coordinating offices.

Diminish and oversee business related voyages: Cancel or defer unimportant travel to territories with local area transmission of COVID-19. Laborers getting back from a region where COVID-19 transmission is happening are observing themselves for manifestations for 14 days and take their temperature two times per day; in the event that they are feeling unwell, they should remain at home, self-detach, and contact a clinical expert.

Danger correspondence, preparing, and instruction: Providing banners, recordings, and electronic message sheets to expand consciousness of COVID-19 among laborers and advancement of safe individual practices at the work environment, give customary data about the danger of COVID-19 utilizing official sources, for example, government offices and WHO, and stress the viability of receiving defensive measures and reducing bits of gossip and deception [10]

Giving evacuee and transient specialists ought to have equivalent admittance to individual defensive gear just as to COVID-19 counteraction, treatment and care, reference, recovery, social assurance, and word related wellbeing administrations, including psychological well-being and psychosocial uphold [11]

Analysts everywhere on the world are dealing with numerical displaying of Covid-19 information to offer the response to questions identified with its transmission elements, moderation, and control measures. Since antibodies to forestall an episode is as yet not found, governments are executing procedures, for example, social removing isolate, control zone, following of the contaminated individuals, travel limitations, $100 \%$ lockdown of zones, dispersion of covers and sanitizers [12, 13, 14].

The bunch control methodology was additionally actualized to contain the infection inside a characterized geographic territory by early location, breaking the chain of transmission and hence forestalling its spread to new regions. 
This would incorporate geographic isolate, social separating measures, improved dynamic observation, testing every single presumed case, disconnection of cases. Following of crown patients is vital to forestall dynamic cases as there are episodes revealed where crown patients attempted to escape from medical clinics. Patients exploited the nonattendance of watchmen and the disconnected territory around the medical clinic to flee. In numerous emergency clinics, police have been sent to prevent patients from being tainted by a Covid from getting away from isolate. $[15,16,17]$.

Present day innovation is consistently adding to the COVID-19 pandemic. The part of information science, AI, and computerized reasoning has been enormously expanded to comprehend the different elements of a pandemic, for example, infection following, forecast of results, computational science, picture preparing, following isolated instances of Coronavirus. Here we are talking about mechanical achievements and the relevance of AI and manmade brainpower for handling pandemic in various.

Medical clinics and specialists are confronting various difficulties because of the Covid-19 flare-up. With restricted assets, treatment is done in an exceptionally controlled climate. Because of the fast change of the Covid, outpatients quickly transformed into basic circumstances. So it is needed to distinguish the cases early and give streamline treatment. Simulated intelligence has an important commitment toward infection following, quiet following, examining, foreseeing, and explaining Coronavirus tainting.

This paper proposes a solution to secure the containment zone as well as to secure a peripheral. The organisation of paper is as follows, section 2 presenting proposed design, section 3 presents implementation, and section 4 presents the results.

\section{Proposed design}

As discussed in the previous sections the proposed design for containment zone is following. There are three modules in the proposed architecture. The details for each module is as following:

\section{Module1: Signal capturing unit:}

This module used to gather data from sensor. In this module IR PIN diode is used as a sensor which detects light from IR laser diode. IR laser diode further connected with beam splitter to split the laser light for multiple segment of fibre cable.

\section{Module 2 - Processing Unit:}

The second module is for processing the algorithms. This module includes a microcontroller to analyse the data and classify the result based on the algorithms. The algorithm is described in the following sections.

\section{Module 3- Transmitter:}

This module includes a transmitter to transmit the event information.

\section{Experimental Setup: Optical Fibre Sensor}

Figure 1 shows single zone arrangement of optical fiber sensor used for signal collection [18]. Each zone has two segments. Two single mode optical fibres kept separated by a distance of $5 \mathrm{~m}$ and buried around 9 inches deep in the soil were used for each segment. The length of fibre optic segments may vary from $10 \mathrm{~m}$ to $2 \mathrm{~km}$ depending on requirement. Each segment has the capability to detect and identify the intruder who walks over the buried optical fiber segment and send a message about the intruder and the segment number on a copper line to a mote. Fibre segments are joined at both ends using couplers. At one end an IR laser beam is injected. A beam splitter (1:4) has been used to energize two pairs of fibres. At the other end, two fibre lines (which were kept separated by around $5 \mathrm{~m}$ ) were brought together by couplers. At the receiving end, an IR PIN diode was used. Each segment has its own PIN diode detector. This diode produces a complex interference pattern. The pattern changes depend upon the stresses on the fibres. This pattern is processed by a processor (ARM processor). Figure 2 shows arrangement of different zones. Different fibre zones can be arranged side by side to cover more area. Each fibre segment has an ID that is sent along with the event information to communicate the crossing point.

We have targeted the animal gait to identify the trespassing animal. The PIN diode signal is invariant to the depth of deployment, nature of soil, weight of the animal, and the speed with which the animal is travelling.

Because of its flexibility, we may use the system in different applications such as virtual fence to detect trespassers, presence of human being and Tiger on tiger trail, human being near water bodies, protect animals crossing railway tracks and high ways in the forests.

After filtering out the noise, the signal is amplified and transmitted to the second module. 


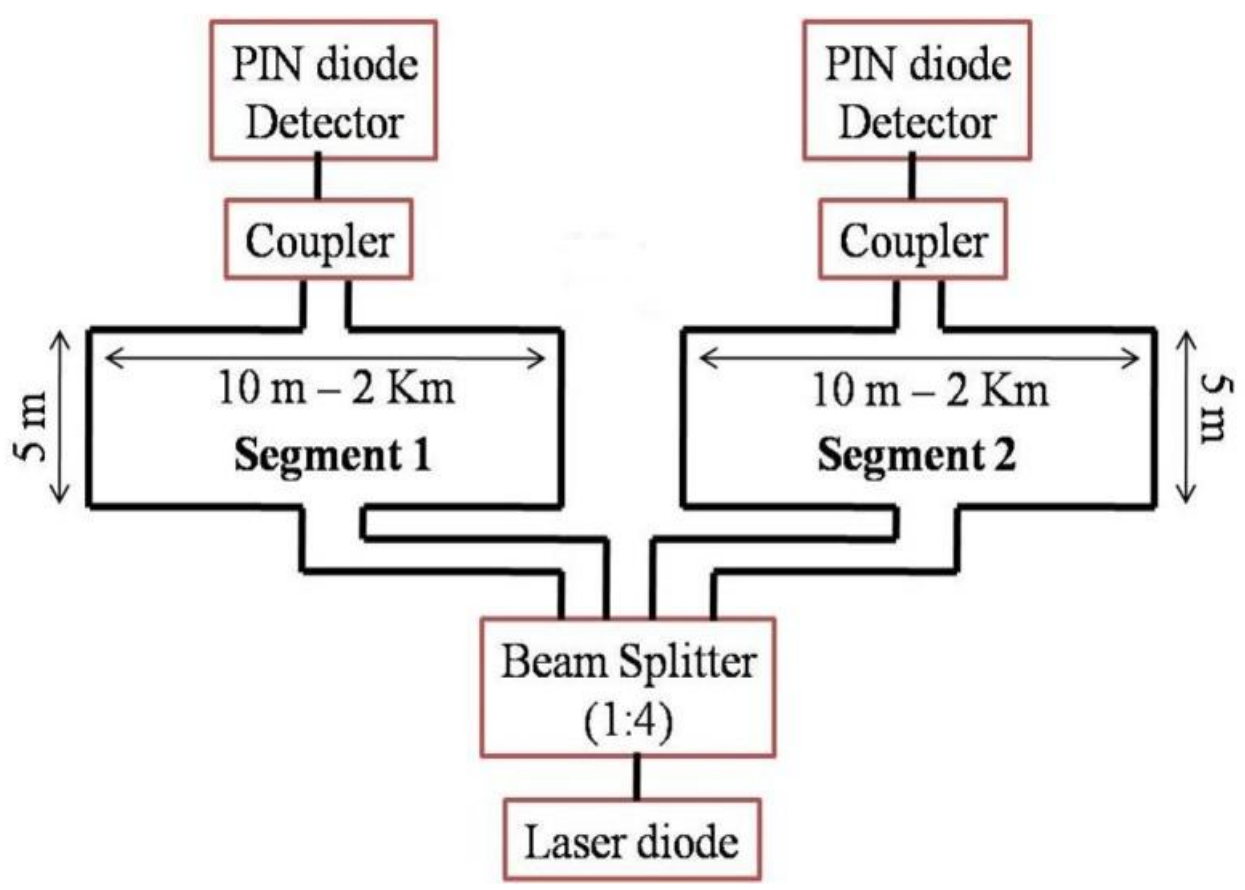

Figure 1: Experimental setup of single fibre zone

Fibre Zone 1

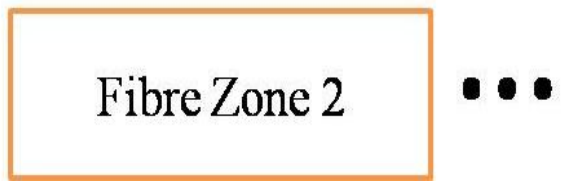

Fibre Zone N

Figure 2: Arrangement of fibers zones

\section{Signal Analysis}

The setup was deployed at the institute campus. The team has collected signals of human movement for 15 days. The signals were analysed using MATLAB.
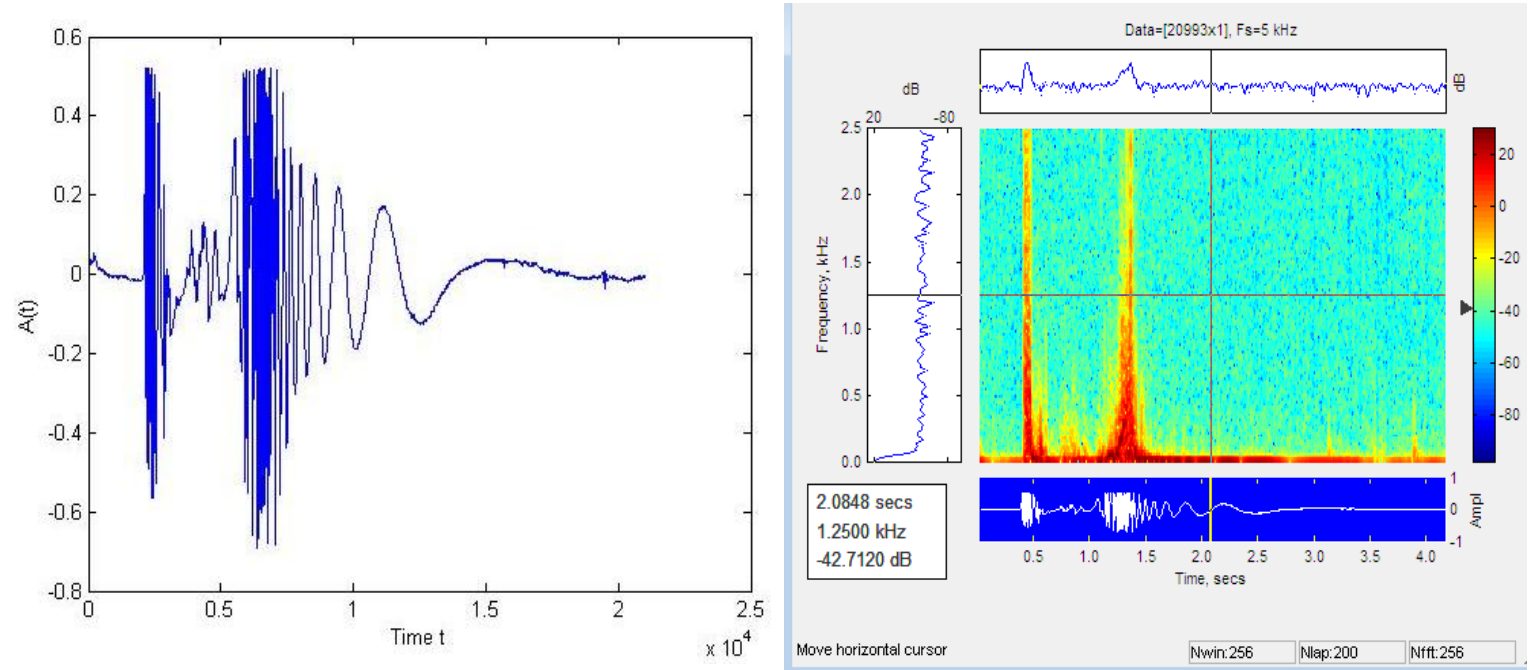

Figure 3: Signal for walk of single person

Figure 3 shows plot of signal and spectrogram of a walk of a single person. It can be observed in the graph there is a peak when person put their feet on cable. 


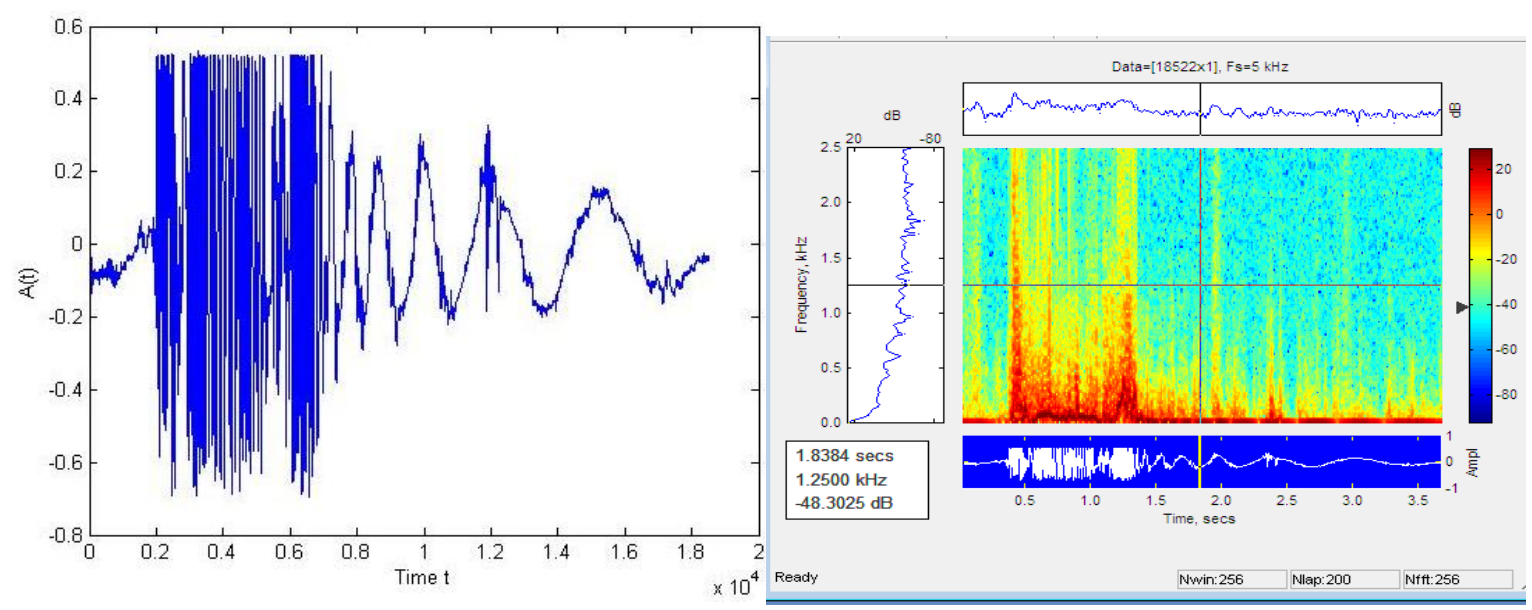

Figure 4: Signal for Running of single person

Figure 4 shows plot of signal and spectrogram of running a single person. It can be observed in the graph there is a peak when person reaches nearby the cable and crosses the sensor cable.

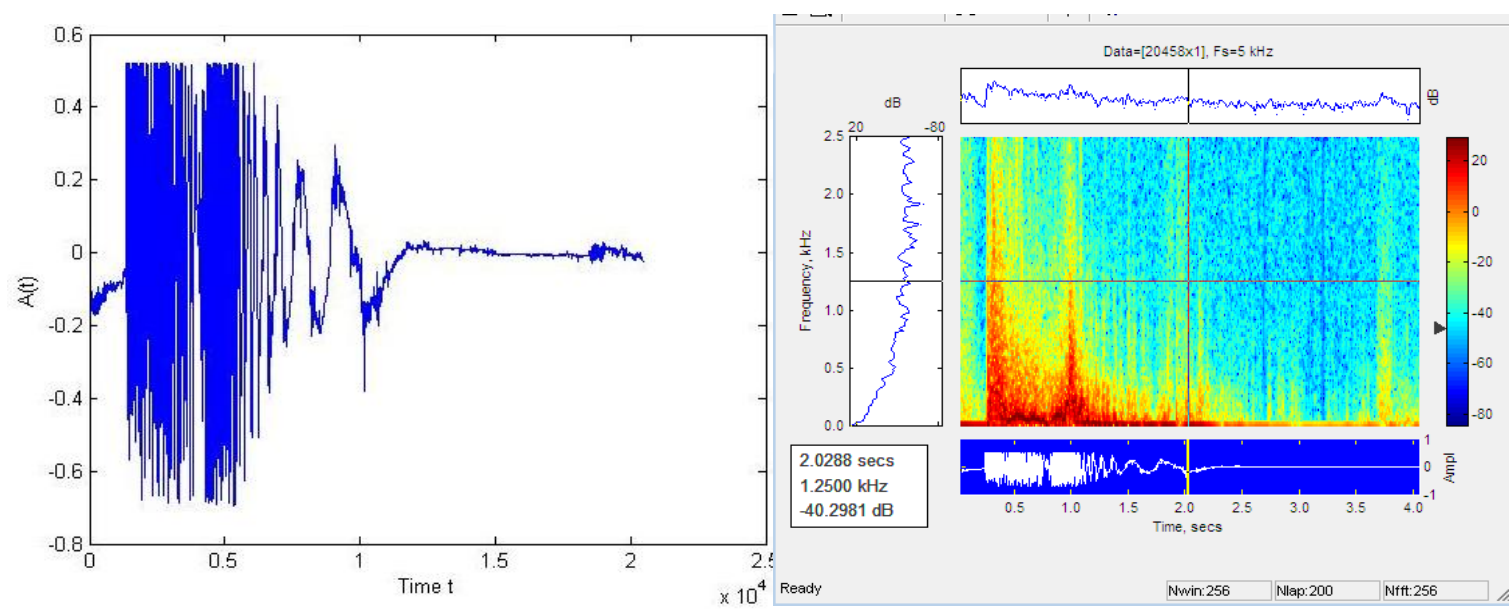

Figure 5: Signal for Jump of single person

Figure 5 shows plot of signal and spectrogram of jump of a single person. It can be observed in the graph there is a peak when person jumps nearby the sensor cable.

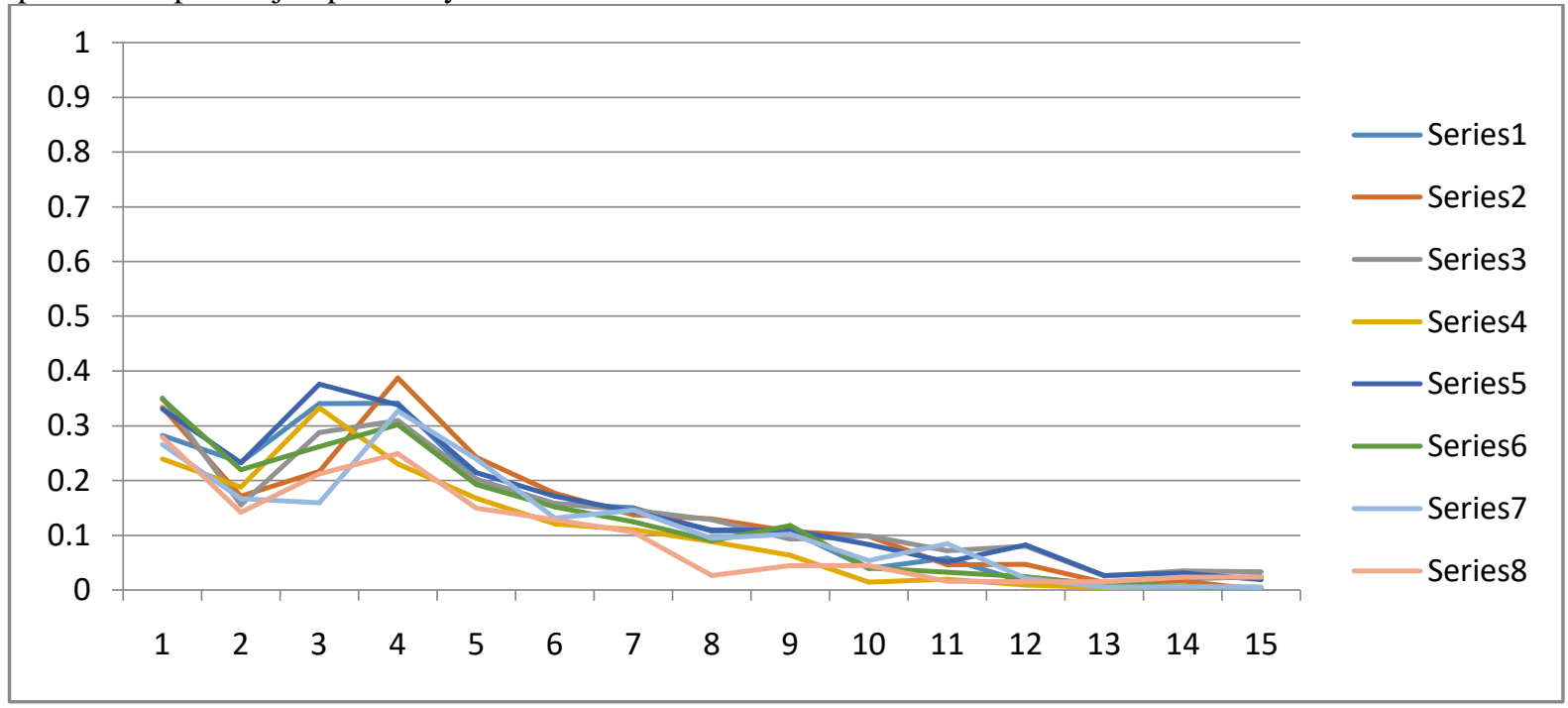

Figure 6: Plot of Signal for walk set 1 


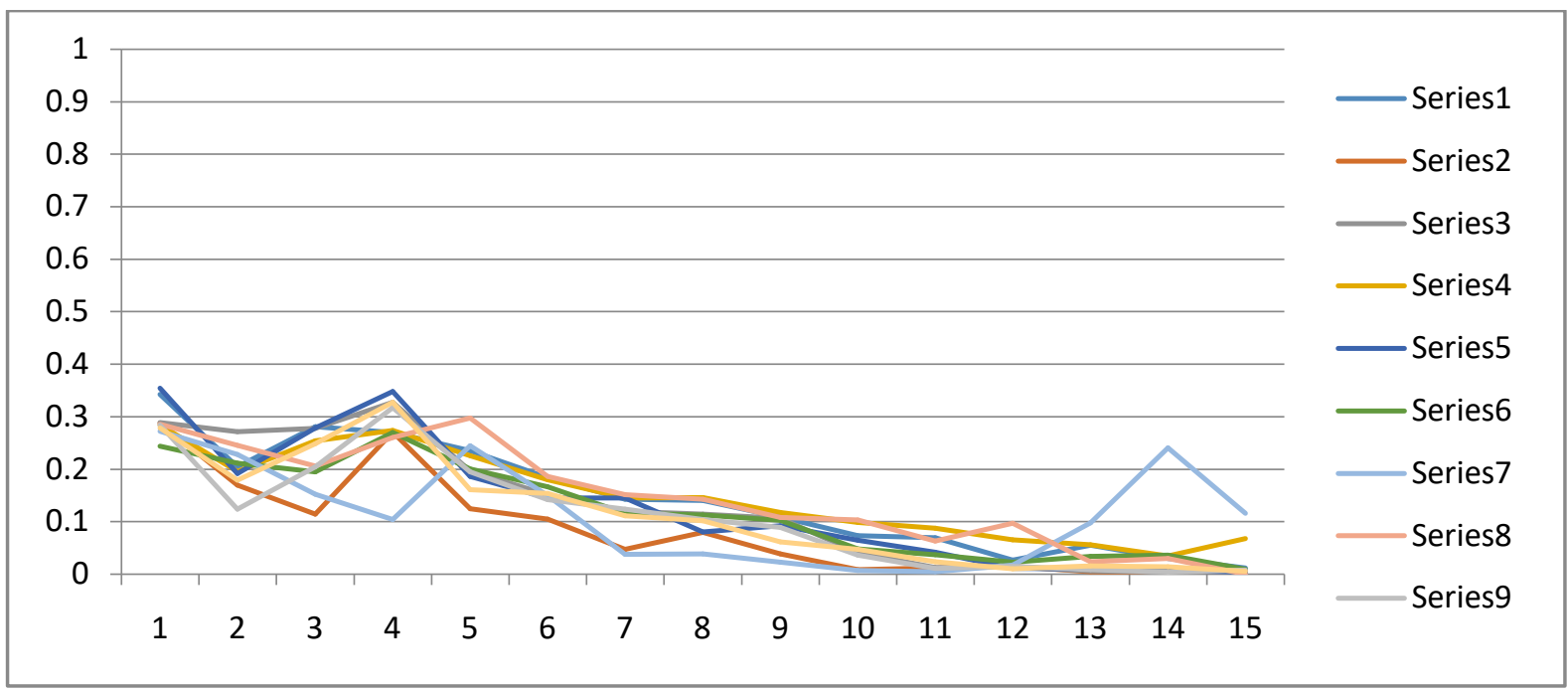

Figure 7: Plot of Signal for walk set 2

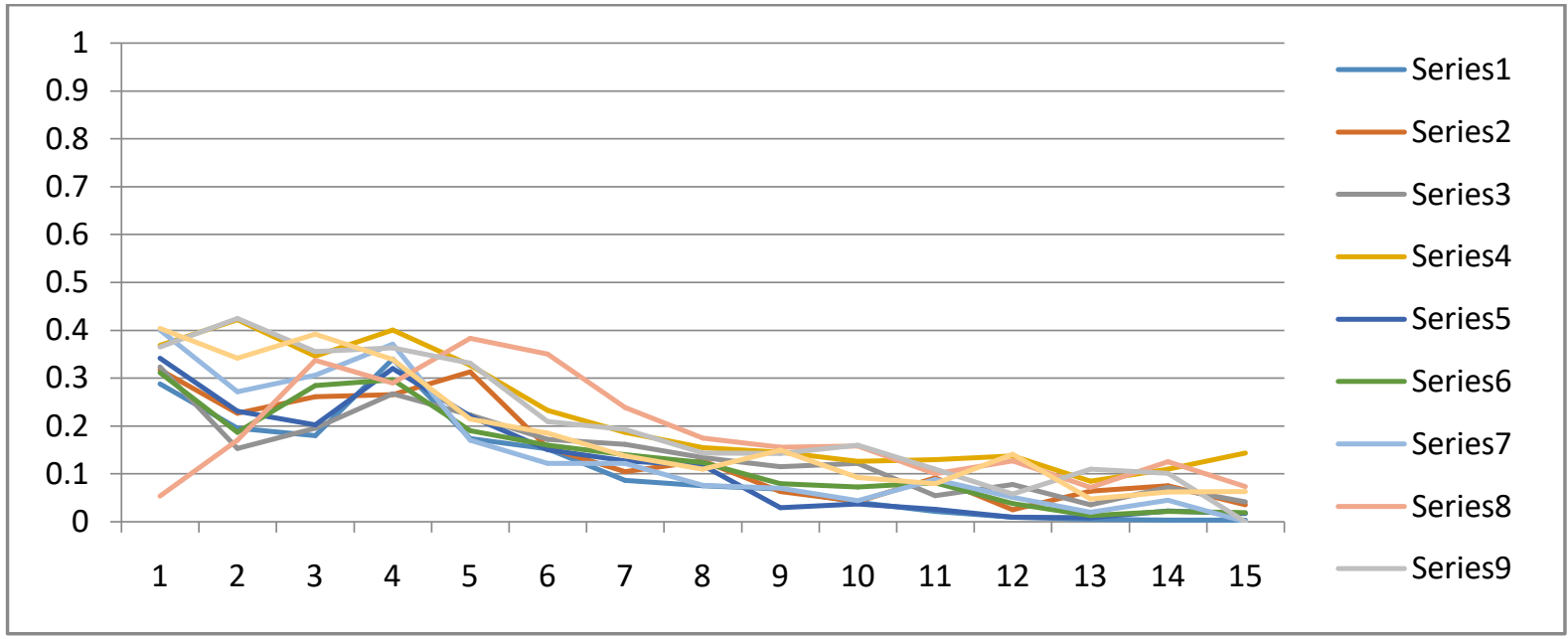

Figure 6: Plot of Signal for walk set 3

The collected signals were divided in 15 parts. After dividing the signal RMS values of each part calculated. RMS values of 15 parts of signals were plotted to observe the pattern of human walk pattern. Figure 5, 6 and 7 shows the pattern of human walk pattern in set of 9 signals. The signals were divided in 20, 25 and 30 parts also, but the pattern of walking can be visualizing in 15 parts of division.

\section{Algorithm for classification}

Figure 7 shows the boundaries for the signals. There are four boundaries created for classification of signals. The lower boundaries were created as average+ standard_deviation and average- standard_deviation respectively. Similarly, the upper boundaries were created as average+ (2*standard_deviation) and average(2*standard_deviation).

If any signal lies between these boundaries, then algorithm will predict that signal as human gait pattern. 


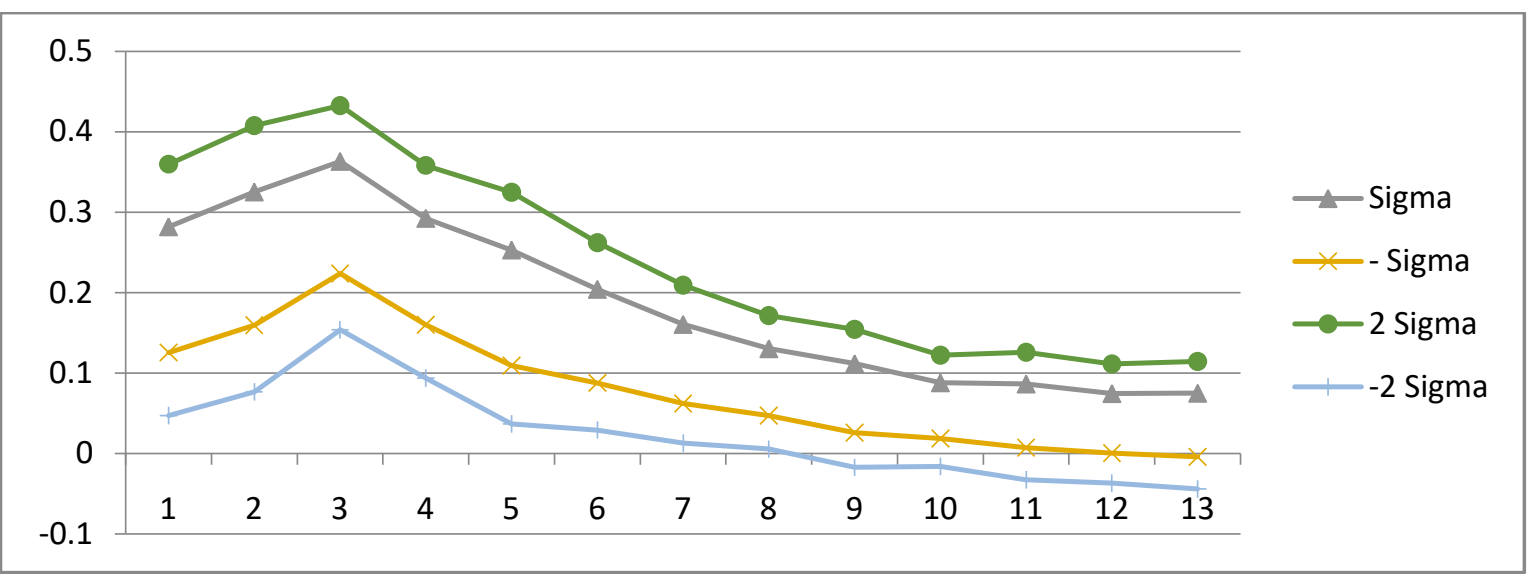

Figure 7: Boundaries plot for the signal

\section{Results}

The setup and algorithms was tested in very regress manner. The testing was done with those persons who were not the part of data collection. A different set of persons were moved on fibre cable sensor randomly. There were very little cases where algorithm was not able to classify.

\begin{tabular}{|l|l|l|}
\hline Total Person & Total detection & Signal not detected \\
\hline 90 & 87 & 03 \\
\hline
\end{tabular}

\section{Conclusion}

Containment zone is required to maintain the distancing between safe and unsafe zone. It can be the case of pandemic, or any security reason. A virtual boundary can always protect people. A virtual boundary will help security persons to manage the security in all areas without much efforts. This paper has presented the solution to create a virtual boundary, which is under the soil. The real time data was collected using the setup and analysed using MATLAB. The algorithm was deployed in a microcontroller. The system was able to identify the human movement, and about $98 \%$ efficient. There are multiple applications where this setup can be implemented. In the future direction the experimental setup will be analysed to check movement of animals

\section{References}

https://www.worldometers.info/coronavirus/

Huang C, Wang Y, Li X, Rem L, Zhao J, Hu Y, et al. Clinical features of patients infected with 2019 novel coronavirus in Wuhan, China. Lancet North Am Ed 2020. doi: 10.1016/S0140-6736(20)30183-5 .

Lai CC, Shih TP, Ko WC, Tang HJ, Hsueh PR. "Severe acute respiratory syn- drome coronavirus 2 (SARS-CoV2) and corona virus disease-2019 (COVID-19): the epidemic and the challenges. Int J Antimicrob Agents 2020;55(3):105924 ISSN 0924-8579.

World Health Organization (WHO). Coronavirus disease 2019 (COVID-19) situ- ation report -70. WHO; 2020 .

hu N, Zhang D, Wang W, Li X, Yang B, Song J, et al. A novel coronavirus from patients with pneumonia in China, 2019. N Engl J Med 2020.

WHO (2020) Considerations in adjusting public health and social measures in the context of COVID-19 (Interim Guidance, 16 April 2020)(WHO 2020). https://www.who.int/publications-detail/considerations-in-adjustingpublic-health-andsocial-measures-in-the-context-of-covid-19-interim-guidance

WHO (2020) Obligatory hand hygiene against transmission of COVID-19, Interim recommendation, 1 April 2020 https://www.who.int/docs/default-source/inaugural-who-partners-forum/who-interim-recommendationon-obligatoryhand-hygiene-against-transmission-of-covid-19.pdf

WHO (2020), Getting your workplace ready for COVID-19, 3 March 2020, ttps://www.who.int/docs/defaultsource/coronaviruse/getting-workplace-ready-for-covid19.pdf?sfvrsn=359a81e7_6

Cirrincione, L. et al (2020) COVID-19 Pandemic: Prevention and Protection Measures to de Adopted at the Workplace, Sustainability 2020, 12(9), 3603; https://doi.org/10.3390/su12093603

Social Stigma associated with COVID-19, UNICEF, WHO, IFRC https://www.who.int/docs/defaultsource/coronaviruse/covid19-stigma-guide.pdf

WHO (2020) Preparedness, prevention and control of coronavirus disease (COVID-19) for refugees and migrants in noncamp settings, WHO https://apps.who.int/iris/rest/bitstreams/1275039/retrieve

Choi SC , Ki M . "Estimating the reproductive number and the outbreak size of Novel Coronavirus disease (COVID-19) using mathematical model in Republic of Korea. Epidemiol Health 2020:e2020011 . 
Hellewell J , Abbott S , Gimma A, Bosse NI , Jarvis CI , Russell TW , Mun- day JD , Kucharski AJ , Edmunds WJ , Sun F , Flasche S . "Feasibility of controlling COVID-19 outbreaks by isolation of cases and contacts. Lancet Global Health 2020;8:e488-96 .

Prem K, Liu Y, Russell TW, Kucharski AJ, Eggo RM, Davies N, Flasche S, Clif- ford S, Pearson CA, Munday JD, Abbott S. "The effect of control trategies to re- duce social mixing on outcomes of the COVID-19 epidemic in Wuhan, China: a modelling study. Lancet Public Health 2020. doi: 10.1016/S2468-2667(20) 30073-6.

https://www.punekarnews.in/pune-covid-patient-runs-away-from-hospital-no-one-stops-as-they-didnt-have-ppe/ https://punemirror.indiatimes.com/pune/civic/suspected-covid-19-case-runs-away-fromhospital/articleshow/74662846.cms

https://indianexpress.com/article/cities/ahmedabad/covid-19-patient-flees-hospital-in-ahmedabad-brought-back$6453968 /$

Preetam Suman et al., "Identification of trespasser from the signatures of buried single mode fiber optic sensor cable," 2015 Annual IEEE India Conference (INDICON), New Delhi, 2015, pp. 1-6 